\title{
TREATMENT OF MANDIBULAR CONDYLE FRACTURE - A COMPARISON OF TWO PROTOCOLS.
}

\footnotetext{
1. BDS, MSc (OMFS)

Phd Scholar Oral Pathology Institute of Dentistry, LUMHS, Jamshoro.

2. BDS, MSc OMFS

Assistant Professor Oral \& Maxillofacial Surgery

Bhittai Dental \& Medical College.

3. BDS, MSc

Assistant Professor

Science of Dental Materials

Department

Institute of Dentistry, LUMHS Jamshoro.

4. BDS, MSc

Ph.D Scholar Oral Pathology Institute of Dentistry, LUMHS, Jamshoro.

5. BDS, MSc (OMFS)

Lecturer Oral \& Maxillofacial Surgery LUMHS.
}

Correspondence Address: Dr. Salman Shams

Oral \& Maxillofacial Surgery LUMHS.

salman_omfs@hotmail.com

Article received on:

31/10/2019

Accepted for publication:

$26 / 12 / 2019$

\begin{abstract}
Zunair Memon ${ }^{1}$, Samreen Naz², Abdul Ghani Shaikh ${ }^{3}$, Zahid Hussain Siyal', Salman Shams ${ }^{5}$
\end{abstract}
ABSTRACT... Objectives: To compare the outcome of two protocols (open reduction and closed reduction) in the treatment of mandibular condyle fracture. Study Design: Comparative study. Setting: Department of Oral \& Maxillofacial Surgery, Institute of Dentistry, Liaquat University of Medical and Health Sciences Jamshoro. Period: January 2016 to September 2016. Material \& Methods: After selection of patient into either group, for closed reduction technique, maxillomandibular fixation was applied for 4-6 weeks. For open reduction, a preauricular incision was given and fracture was reduced and fixed with miniplates after achieving the normal occlusion. Post operatively, patients of both the group were recalled after one, two and three months for the assessment of the functional effects such as occlusion and range of motion in both groups. Results: Mean age of the patients was $29.80+4.42$ years in group 1 (open reduction group), while mean age of the group 2 (closed reduction group) was $23.95+6.63$ years. Male were in the majority in both groups 17 in group 1 and 16 in group 2 . Out of 20 patients in group 1, 11 patients had condylar neck fracture and 9 had subcondyle fracture. While in group 2, 13 patients had subcondyle fracture and 7 had condylar neck fracture. In both groups again no significant difference was found according to location of the fracture (p-value 0.20). Group 1 (open reduction) had better functional results in terms of occlusion and range of motion after 3 months as compared to the group 2 (closed reduction). P-value 0.19 . Conclusion: In dealing with mandibular condyle fractures it was concluded that open reduction and internal fixation is a better technique as compared to the closed reduction with maxillomandibular fixation.

Key words: $\quad$ Closed Reduction, Mandibular Condyle Fracture, Open Reduction.

Article Citation: Memon Z, Naz S, Shaikh AG, Siyal ZH, Shams S. Treatment of mandibular condyle fracture - a comparison of two protocols. Professional Med J 2020; 27(10):2176-2181. DOI: 10.29309/TPMJ/2020.27.10.4310

\section{INTRODUCTION}

The bone which has the compound role in esthetics of the face and efficient occlusion is solely the mandible. Mandibular fractures are the most common fractures of the facial skeleton as they have the famous position in lower jaw, and it accounts for $36 \%$ to $59 \%$ of all maxillofacial fractures. ${ }^{1,2}$ The mandibular fracture varies according to centers and countries, with the condyle, angle and symphysis as the most frequently encountered fracture site. ${ }^{3}$

Condyle fracture occurs most frequently and in dentate and edentulous patients it accounts for about $30 \%$ and $37 \%$ of mandible fractures respectively. ${ }^{4}$ Pain, limited mandibular movement, muscle spasm, deviation of the mandible, malocclusion, pathological changes in the temporomandibular joint, facial unevenness and ankylosis are the mostly encountered problems with fractures of mandibular condyle. ${ }^{5}$ Mandibular condyle fracture can be classified as unilateral or bilateral; according to the fracture position (condyle head, condyle neck and subcondyle) and according to the degree of fracture displaced (non-displaced, deviated, displaced and dislocated). ${ }^{4}$

The common etiological factors of mandibular condyle fractures are road traffic accidents, falls, firearm injuries, interpersonal violence, sports injuries and industrial accidents. ${ }^{6}$

The treatment options of unilateral condyle 
fractures are open reduction and internal fixation or closed reduction with maxillomandibular fixation; however, for either closed or open technique, the success of the treatment relies on the restoration of normal dental occlusion and bony union. ${ }^{7}$ Both methods of management have their own advantages and disadvantages. Closed reduction does not upset the vascular envelope, less costly for the patient, no jeopardy to facial nerve and can be managed under local anesthesia; but it carries a drawback of having mouth closed and a extensive period of immobilization. It also requires the dentition being intact, uneasy for the patients and in terms of oral hygiene maintenance it grossly requires patient's fulfillment. Advantages achievable with open reduction are: direct visualization and reduction of fractured bone segments and restoration of the patient's pre injury occlusion without maxillomandibular fixation; this permit for bony healing in a shorter phase of time (primary bone healing), enhanced nutrition and oral hygiene; however, possible foreign body infections are more expected with this method and it carries a momentous danger of facial nerve traction injury. ${ }^{8}$

The recommended treatment of bilateral mandibular condyle fracture is open reduction and internal fixation of at least one condyle followed by maxillomandibular fixation for certain period of time. There are two thoughts of management of unilateral condyle fracture that makes it still controversial, as some favors close reduction with MMF and other group prefers open reduction with internal fixation. 9,10 $^{-1}$

The aim of this study was to compare the outcome of unilateral mandibular condyle fracture treated by open reduction and internal fixation with closed reduction with maxillomandibular fixation.

\section{MATERIAL \& METHODS}

This comparative analytical study with non probability purposive technique was conducted at department of oral and maxillofacial surgery Hyderabad/Jamshoro.

Total Sample size was divided in to two groups Group A (Open Reduction) = 20 Patients Group B (Closed Reduction) = 20 Patients

\section{INCLUSION CRITERIA}

- Patient having unilateral non comminuted low condylar fracture.

- Patient in age group 15-50.

- Patient with either gender.

- Patient with sufficient bilateral dentition to allow Maxillomandibular Fixation.

\section{EXCLUSION CRITERIA}

- Patient with bilateral condyle fracture.

- Patient with undisplaced condyle with normal occlusion.

- Patient not medically fit to undergo surgical intervention.

- Patient not willing to participate in this study.

\section{DATA COLLECTION TECHNIQUE}

Patients meeting the inclusion criteria coming through OutPatientDepartment(OPD) and through emergency department were included in this study. Personal details of patient including name, age, gender, hospital registration number were recorded on Proforma. Diagnosis of mandibular condyle fracture was done on the basis of clinical examination, Orthopantomography (OPG) and P.A view of face. Random allocation was done by lottery method: odd number were treated with open reduction with internal fixation and even number were treated with closed reduction with maxillomandibular fixation.

For open reduction and internal fixation the patient was prepared for general anesthesia and the surgical area was cleaned with antiseptic before starting surgery. The fracture area was reduced with the instrument manually and fixed with miniplates (5 holes titanium miniplates with 4 screws having the size of $6 \mathrm{~mm}$, Moin International, Made in Pakistan). The patient was discharged from the hospital and requested for follow-up after one, two and three months for the assessment of the functional effects such as occlusion and range of motion.

For closed reduction with maxillomandibular fixation once arch bar was secured, cross intermaxillary wires were used to obtain pre-injury occlusion and fixation. The patient mouth was closed and advised to take only soft and liquid 
diet for next 4-6 weeks. The standard antibiotics with analgesic in syrup were prescribed for 5 days. Oral hygiene instructions were given and mouthwash was prescribed to maintain good oral hygiene. The patient was discharged from the hospital and requested for follow-up after one, two and three months for the assessment of the functional effects such as occlusion and range of motion.

\section{RESULTS}

Mean age of the patients was $29.80+4.42$ years in group 1 (open reduction group), while mean age of the group 2 (closed reduction group) was $23.95+6.63$ years (Table-I). Male were in the majority in both groups 17 in group 1 and 16 in group 2 (Table-II). Out of 20 patients in group 1, 11 patients had condylar neck fracture and 9 had subcondyle fracture, while in group 2, 13 patients had subcondyle fracture and 7 had condylar neck fracture (Table-III). In both groups again no significant difference was found according to location of the fracture ( $p$-value 0.20). Group 1 (open reduction) had better functional results in terms of occlusion and range of motion after 3 months as compared to the group 2 (closed reduction) P-value 0.19. (Table-IV to VI)

\begin{tabular}{|c|c|c|c|}
\hline Age & \multicolumn{2}{|c|}{ Mean+ STD. } & P-Value \\
\hline Group-1 & \multicolumn{2}{|c|}{$29.80+4.42$} & \multirow{2}{*}{0.002} \\
\hline Group-2 & \multicolumn{2}{|c|}{$23.95+6.63$} & \\
\hline \multicolumn{4}{|c|}{ Table-I. Distribution of cases according to age $\mathbf{N}=20$} \\
\hline \multirow[b]{2}{*}{ Gender } & \multicolumn{2}{|c|}{ Group } & \multirow[b]{2}{*}{ P-Value } \\
\hline & $\begin{array}{c}\text { Open } \\
\text { Reduction }\end{array}$ & $\begin{array}{c}\text { Closed } \\
\text { Reduction }\end{array}$ & \\
\hline Male & 17 & 16 & \multirow{2}{*}{0.144} \\
\hline Female & 03 & 04 & \\
\hline
\end{tabular}

Table-II. Distribution of cases according to gender

\begin{tabular}{|c|c|c|c|}
\hline \multirow[b]{2}{*}{ Condyle } & \multicolumn{2}{|c|}{ Group } & \multirow[b]{2}{*}{ P-Value } \\
\hline & $\begin{array}{c}\text { Open } \\
\text { Reduction }\end{array}$ & $\begin{array}{c}\text { Closed } \\
\text { Reduction }\end{array}$ & \\
\hline Sub condyle & 9 & 13 & \multirow{2}{*}{0.20} \\
\hline Condylar neck & 11 & 7 & \\
\hline
\end{tabular}

Professional Med J 2020;27(10):2176-2181.

\begin{tabular}{|c|c|c|c|}
\hline \multirow[b]{2}{*}{1 Month } & \multicolumn{2}{|c|}{ Group } & \multirow[b]{2}{*}{ P-Value } \\
\hline & $\begin{array}{l}\text { Open } \\
\text { Reduction }\end{array}$ & $\begin{array}{l}\text { Closed } \\
\text { Reduction }\end{array}$ & \\
\hline \multicolumn{3}{|l|}{ Occlusion } & \multirow{3}{*}{0.04} \\
\hline Good & 16 & 13 & \\
\hline Poor & 04 & 07 & \\
\hline \multicolumn{4}{|c|}{ Range of motion } \\
\hline Good & 10 & 06 & 0.05 \\
\hline Poor & 10 & 14 & \\
\hline \multicolumn{4}{|c|}{$\begin{array}{l}\text { Table-IV. Distribution of cases according to } 1 \text { month } \\
\text { occlusion and range of motion }\end{array}$} \\
\hline \multirow[b]{2}{*}{2 Month } & \multicolumn{2}{|c|}{ Group } & \multirow[b]{2}{*}{ P-Value } \\
\hline & $\begin{array}{l}\text { Open } \\
\text { Reduction }\end{array}$ & $\begin{array}{l}\text { Closed } \\
\text { Reduction }\end{array}$ & \\
\hline \multicolumn{3}{|l|}{ Occlusion } & \multirow{3}{*}{0.07} \\
\hline Good & 18 & 14 & \\
\hline Poor & 02 & 06 & \\
\hline \multicolumn{4}{|c|}{ Range of motion } \\
\hline Good & 15 & 09 & 0.06 \\
\hline Poor & 05 & 11 & \\
\hline \multicolumn{4}{|c|}{$\begin{array}{l}\text { Table-V. Distribution of cases according to } 2 \text { month } \\
\text { occlusion and range of motion } n=20\end{array}$} \\
\hline \multirow[b]{2}{*}{3 Month } & \multicolumn{2}{|c|}{ Group } & \multirow[b]{2}{*}{ P-Value } \\
\hline & $\begin{array}{l}\text { Open } \\
\text { Reduction }\end{array}$ & $\begin{array}{l}\text { Closed } \\
\text { Reduction }\end{array}$ & \\
\hline \multicolumn{3}{|l|}{ Occlusion } & \multirow{3}{*}{0.19} \\
\hline Good & 19 & 16 & \\
\hline Poor & 00 & 02 & \\
\hline Total & 19 & 18 & \\
\hline \multicolumn{4}{|c|}{ Range of motion } \\
\hline Good & 18 & 14 & 0.09 \\
\hline Poor & 01 & 04 & \\
\hline
\end{tabular}

\section{DISCUSSION}

In this study mean age of the patients was29.80+4.42 years in open reduction group, while mean age of the closed reduction group was $23.95+6.63$ years. Comparable findings were found by Badar MA et al. ${ }^{13}$ In his study of 70 patients, $80 \%$ were males. The age ranged from 5 to 47 years. Majority of patients were in age group 21-30 years (40\%) followed by 11 20 years $(25.7 \%)$. As well as in this study male were in the majority in both groups 17 in group 1 and 16 in group 2 out of 20 from each group, 
while 3 females were in group 1 and 4 in group 2. Another study carried out by Rasheed A et $\mathrm{al}^{14}$ which included sixty dentate patients having condylar and associated mandibular factures. The sample included 38 (63.3\%) males and 22 $(36.6 \%)$ females. Majority of the patients are male because fractures were mostly associated with road traffic accident and fall from height, and since males are more involved in outdoor activities they are more exposed to these risk factors as compared to females. On other hand Rampaso $\mathrm{CL}$ et $\mathrm{al}^{15}$ found males representing $72.0 \%$ of the sample, the age group most affected being the one between 21 and 30 years.

In our study right side was more often involved than the left side in both groups, without significant difference 0.50 . In group 1 out of 20 patients, 12 had right side fracture and 8 had left side fracture. While in group 2, 14 patients were with right side fracture and 6 had left side fracture out of 20 cases. Rasheed $\mathrm{A}$ et $\mathrm{al}^{14}$ also found majority of cases with right side 32 and 28 had involved left side.

In our series, out of 20 patients in group 1, 11 patients had condylar neck fracture and 9 had sub condyle fracture. While in group 2, 13 patients had subcondyle fracture and 7 had condylar neck fracture. In both groups no significant difference was found according to type of fracture $p$-value 0.20 . Akinbami BO et $\mathrm{al}^{16}$ reported that $(72.7 \%)$ of the patients with condyle fracture had associated fractures affecting other sites of the mandible while $3(27.3 \%)$ patients had isolated condyle fractures, the lower neck of the condyle was the site most commonly involved with 9 (64.3\%) cases while the subcondyle was affected in 3 $(21.5 \%)$ cases respectively.

In our series according to the assessment of function after 1 month post-surgery, patients who underwent open reduction had good occlusion and good range of motion as compared to the closed group. P-value 0.05. Authors now have came to the conclusion that if the technique is minimally invasive than open reduction is also possible in paediatric patients in managing condylar fractures. ${ }^{17}$ Factors that have gained priority in managing these fractures by open reduction is mainly the development, while surgeons with confidence and great experitise in dealing with internal rigid fixation are also important. ${ }^{18}$

Various studies reported that cases where condyle is displaced into middle cranial fossa, inappropriate occlusal restoration by closed reduction and lateral extracapsular displacement are the absolute indications where open reduction and internal fixation has to be carried out. ${ }^{19-22}$

In our study functional assessment in terms of occlusion and range of motion after 2 and 3 month, group 1 (patients who underwent open reduction and internal fixation) had good occlusion and good range of motion as compared to the group 2 (closed reduction with maxillomandibular fixation) but no significant difference was found. P-value0.06. In the study of the Santleret $\mathrm{al}^{23}$ two hundred thirty-four patients with fractures of the mandibular condylar process were treated by open or closed methods. On the basis of radiological, objective and clinical examination 150 patients with a mean follow-up time of 2.5 years were analyzed. While comparing surgical and non surgical treated cases no noteworthy dissimilarity in mobility, joint troubles, occlusion, muscle pain or nerve disorders were observed. Marker et $\mathrm{al}^{24}$ in his study informed that treating fractures of condyle by closed reduction is non distressing, secure and dependable and rarely cause instability of function and malocclusion.

\section{CONCLUSION}

It was concluded that open reduction and internal fixation is better technique as compared to the closed reduction with maxillomandibular fixation in the treatment of mandibular condyle fracture. Open reduction and internal fixation showed good occlusion and range of motion till 2 months follow-up, while after three month followup outcome was non-significant in both groups. More randomized research is needed for further confirmation and accurate results as the sample size was small for definite conclusions to be drawn.

Copyright@ 26 Dec, 2019. 


\section{REFERENCES}

1. Natu SS, Pradhan H, Gupta H et al. An epidemiological study on pattern and incidence of mandibular fractures. Plast Surg Int. 2012; 2012.

2. Ghodke MH, Bhoyar SC, Shah SV. Prevalence of mandibular fractures reported at C.S.M.S.S dental college, Aurangabad from February 2008 To September 2009. J Int Soc Prev Community Dent. 2013; 3(2):51-58.

3. Chrcanovic BR, Abreu MH, Freire-Maia B, Souza LN. 1,454 mandibular fractures: A 3-year study in a hospital in Belo Horizonte, Brazil. J Craniomaxillofac Surg. 2012; 40:116-23.

4. Choi KY, Yang JD, Chung HY et al. Current concepts in the mandibular condyle fracture management Part 1: Overview of condylar fracture. Arch Plast Surg. 2012 Jul; 39(4):291-300.

5. Hassan SG, Shams S, Rehman M, Kumar S, Hamid S. Mandibular condyle fractures; A 2 years study at Liaquat University Hospital. Professional Med J 2016; 23(6):705-8.

6. Khan A, Khitab U, Khan MT, Salam A. A Comparative analysis of rigid and non-rigid fixation in mandibular fractures: A prospective study. Pak Oral Dent J; 2010; 30(1):62-67.

7. Chandra Shekar BR, Reddy C. A five year retrospective statistical analysis of maxillofacial injuries in patients admitted and treated at two hospitals of Mysore city. Indian J Dent Res. 2008; 19:304-8.

8. Spinzia A, Patrone R, Belli E, Dell'Aversana Orabona G, Ungari $C$, Filiaci $F$, et al. Open reduction and internal fixation of extracapsular mandibular condyle fractures: A long-term clinical and radiological follow-up of 25 patients. BMC Surg. 2014; 7:14-68.

9. Mahgoub MA, El-Sabbagh AH, Abd El-Latif EA, Elhadidy MR. Condylar fractures: Review of $\mathbf{4 0}$ cases. Ann Maxillofac Surg 2018; 8:19-27.

10. Koshy JC, Feldman EM, et al. Pearls of mandibular trauma management. Semin Plast Surg 2010 Nov; 24(4):357-374.

11. Moreno JC, Fernandez A, Ortiz JA, et al. Complication rates associated with different treatments for mandibular fractures. J Oral Maxillofac Surg. 2000; 58:273-280.
12. Balasubramaniam R, Van Sickels J, Falace D. Condylar resorption following temporomandibular joint arthroscopy in a patient with essential thrombocythemia. Oral Surg Oral Med Oral Pathol Oral Radiol Endod. 2006; 101:581-587.

13. Badar MA, Syed SA. Etiology of mandibular condylar fractures; A study from Tertiary Care Hospital of Lahore. PODJ 2014; 34(1):42-45.

14. Rashid A, Mumtaz M, Bhatti MU. Comparison of surgical with nonsurgical treatment for fractured mandibular condyle--a study. Pakistan Oral \& Dental Journal. 2010 Dec 1; 30(2).

15. Rampaso CL, Mattioli TM, Andrade Sobrinho JD, Rapoport A. Evaluation of prevalence in the treatment of mandible condyle fractures. Revista do ColégioBrasileiro de Cirurgiões. 2012 Oct; 39(5):373-6.

16. Akinbami BO, Akadiri OA. Classification and management of mandibular condyle fractures in a Tertiary Health Center. Surgical Science. 2013 Jul 23; 4(08):339.

17. Zimmermann CE, Troulis MJ, Kaban LB. Pediatric facial fractures: recent advances in prevention, diagnosis and management. Int $\mathrm{J}$ Oral and Maxillofacial Surgery 2005; 34: 823-33.

18. Landes CA, Lipphardt R. Prospective evaluation of a pragmatic treatment rationale: Open reduction and internal fixation of displaced and dislocated condyle and condylar head fractures and closed reduction of non-displaced, non-dislocated fractures. Part I: condyle and subcondylar fractures. Int $\mathrm{J}$ Oral and Maxillofacial Surgery 2005; 34: 859-70.

19. Valiati R, Ibrahim D, Abreu MER et al. The treatment of condylar fractures: To open or not to open? A critical review of this controversy. Int J Med Sci. 2008; 5(6):313318.

20. Terai $H$, Shimahara M. Closed treatment of condylar fractures by intermaxillary fixation with thermoforming plates. British Journal of Oral and Maxillofacial Surgery 2004; 42: 61-3.

21. Tominaga K, Habu M, Khanal A, Mimori Y, Yoshioka I, Fukuda J. Biomechanical evaluation of different types of rigid internal fixation techniques for subcondylar fractures. J Oral Maxillofac Surg 2006; 64: 1510-16.

22. Brandt MT, Haug RH. Open versus closed reduction of adult mandibular condyle fractures: A review of the literature regarding the evolution of current thoughts on management. J Oral Maxillofac Surg 2003; 61: 132432. 
23. Santler G, Kärcher H, Ruda C, Köle E. Fractures of the condylar process: surgical versus nonsurgical treatment. J Oral Maxillofac Surg 1999; 57: 392-7.
24. Marker P, Nielsen A, Lehmann Bastian $\mathrm{H}$. Fractures of the mandibular condyle. Part 2: results of treatment of 348 patients. British Journal of Oral and Maxillofacial Surgery 2000; 38: 422-6.

\section{AUTHORSHIP AND CONTRIBUTION DECLARATION}

\begin{tabular}{|c|c|c|c|}
\hline Sr. \# & Author(s) Full Name & Contribution to the paper & Author(s) Signature \\
\hline 1 & Zunair Memon & $\begin{array}{l}\text { Principal author, Data } \\
\text { collection. }\end{array}$ & \\
\hline 2 & Samreen Naz & Discussion. & \\
\hline 3 & Abdul Ghani Shaikh & Manuscript designing. & \\
\hline 4 & Zahid Hussain Siyal & References. & \\
\hline 5 & Salman Shams & Resutls \& Proof read. & \\
\hline
\end{tabular}

